\title{
RRG and the Exploration of Syntactically Based Relativistic Effects
}

\section{Caleb Everett}

In the last two decades there has been a florescence of experimental research demonstrating that crosslinguistic disparities foster differences in nonlinguistic thought across human populations. The linguistic influences on thought that have been uncovered are associated with a number of cognitive phenomena including spatial orientation, quantity recognition, color perception, gender discrimination, and others (Everett 2013). While the extent of such 'relativistic' effects remains a matter of some debate, their existence is now generally incontrovertible. Significantly, most of the effects in question relate to crosslinguistic semantic variation instantiated lexically and/or morphologically. One question that remains largely unexplored in such research is whether syntactic crosslinguistic disparities yield differences in the way speakers construe associated entities and relationships in nonlinguistic contexts. For instance, as McGregor (2009) notes, it is unclear whether speakers of syntactically ergative languages differentiate nonlinguistic concepts (e.g. agency in perceived events) in a more 'ergative' manner than speakers of non-ergative languages. In this chapter I suggest that the framework of Role and Reference Grammar (Van Valin 2005, 2009 inter alia) could be fruitfully utilized in the exploration of potential syntactic effects on nonlinguistic thought. The strong typological grounding of RRG and its characteristic lack of presuppositions about putatively universal syntactic phenomena such as subject-hood (along with its associated rejection of opaque movement rules and null elements in syntax) make it an ideal approach for distinguishing some of the core ways in which syntactic dissimilarities across languages might create disparities in nonlinguistic thought. I conclude that RRG-specific claims about the 
way languages differ syntactically, for instance by relying on actor-based PSA's or undergoer-based PSA's, reveal interesting ways in which researchers might empirically explore the influence of syntactic variation on nonlinguistic cognition.

\section{Introduction}

Researchers in a variety of disciplines have long been fascinated with the following question: Are humans' thought processes influenced by their native language? Put differently, is there evidence for cross-cultural disparities in cognition that owe themselves in some fundamental manner to the languages of the cultures in question? The search for answers to such interrelated questions, i. e. investigation into the topic of 'linguistic relativity', has long stood at the nexus of anthropology, linguistics, and psychology. While the linguistic relativity hypothesis remains closely associated with the work of Edward Sapir and, most significantly, Benjamin Whorf, related ideas have been promulgated over the course of centuries by numerous researchers and philosophers (see Lucy 1992). Nevertheless, the work of Whorf in particular brought the notion to the forefront of discussions on human language and cognition. Subsequent to Whorf's, work, however, the influence of the core ideas of linguistic relativity receded, in large measure due to the rising tide of universalist, innatist theories of human language. In turn, however, linguistics has begun to pay more serious attention to the profound extant linguistic diversity, and the influence of universalist approaches to language and human cognition have now begun to recede. (See e. g. the discussion in Evans \& Levinson 2009.)

In the contemporary intellectual climate, in which many linguists consider the understanding of fundamental linguistic diversity to be a sine qua non of their research programs, and in which linguists increasingly rely on experimental and quantitative methods standard to other branches of the social sciences, there has been an associated resurgence of work on linguistic relativity. Unlike the work of Whorf and many others, this more recent work relies on nonlinguistic experiments, conducted across groups of speakers of different languages. In many cases these experiments are, crucially, informed by detailed ethnographic and linguistic studies.

The florescence of experimental research on linguistic relativity was germinated by the contributions of many scholars (including Whorf), but clearly grew 
out of the work of contemporary researchers such as John Lucy and Stephen Levinson. In the last two decades, and most visibly in the last few years, there have been dozens of studies published on the topic, many in highly visible journals. This research has uncovered evidence for linguistic effects on thought processes associated with numerous cognitive domains, including spatial orientation, color perception, gender discrimination, and quantity recognition, inter alia. For a comprehensive survey of this recent research, I refer the reader to Everett (2013a).

Despite the variety of cognitive domains addressed by the current crop of research on this topic, it is restricted somewhat in terms of the kinds of linguistic phenomena it addresses. Put simply, the vast majority of the work on this topic examines the role of crosslinguistic variation associated with lexical and morphological variables. Many studies examine, for instance, different recurring metaphors that are instantiated at the phrasal level in given languages, but the studies do not specifically address the potential role of syntactic variation in fostering cognitive differences across populations. This is perhaps not surprising, since it is unclear what sorts of hypotheses one might generate vis-à-vis any association between syntax and nonlinguistic thought. In contrast, the clear semantic implications of many lexical and morphological differences between languages yield clear testable predictions regarding nonlinguistic cognitive processes. For instance, in Everett (2013b) I note that the members of two populations without access to lexical or morphological means of denoting numerical concepts struggle with the mere differentiation of exact quantities greater than three. This conclusion is based on experimental work carried out by several researchers (including myself) among the populations in question, and such claims are not based simply on linguistic facts. Nevertheless, one can see how the linguistic facts in this case could generate a testable hypothesis: Speakers of the two groups in question do not have particular lexical and morphological categories (cardinal numerals and number inflection, respectively) common to most languages. The testable hypothesis is readily discernible because of the clear association between these grammatical categories and semantic categories. Such an association is not typically available in the case of syntactic phenomena. Nevertheless, I would like to suggest that the existence of syntactically motivated relativistic effects could be explored. While I remain agnostic with respect to their existence, that existence cannot be ruled out without careful nonlinguistic experimentation conducted with speakers of languages that vary significantly according to some syntactic parameter. 
(After all, a number of the recently uncovered relativistic effects were once ruled out-most notably in the case of linguistic effects on the discrimination of colors.) In order to generate adequate testable hypotheses regarding this matter, however, it would be useful to have a guiding framework. I would like to suggest that Role and Reference Grammar could serve as such a framework, for the reasons that will crystallize in the subsequent discussion. In short: RRG serves as an ideal approach towards framing such research since it relies heavily on meaning, always heeding the interaction of semantic and syntactic variation. In addition, RRG is typologically well grounded, and so it can be used to generate hypotheses regarding the major typological disparities evident in crosslinguistic syntactic data.

\section{Some related research}

As I note in Everett (2013a), there is at least some research that addresses relativistic effects that relate to syntactic phenomena, even if the research does not directly address the role of syntactic variation in fostering relativistic effects. In a recent pilot study (Everett 2014), I examined the potential effects of a semantic transitivity/intransitivity distinction on speakers' nonlinguistic construal of actions. This study was undertaken in part to begin exploring the possibility of the influence of ergative linguistic phenomena on nonlinguistic thought. (The possibility of such an influence was presented by McGregor (2009). $)^{1}$ It is worth recapitulating some of the basic findings of the pilot study, since its results demonstrate a) that it is not unreasonable to think that fundamental syntactic variation may yield some disparities in nonlinguistic thought, and b) how RRG can prove useful in attempting to uncover such disparities. The latter point is particularly relevant, of course, in a book honoring Van Valin's sizable contributions to the typologically oriented study of grammar.

Some background information is in order. Karitiâna is a Tupí language spoken by about 330 individuals in southern Amazonia. The language has been described by several linguists, beginning with David Landin (Landin 1984). In my own research on the language, I have focused on some of its more typologically remarkable features, most notably the pattern of random-like nasal variation that

1 It is worth mentioning that some of Van's earlier major contributions to the field addressed ergativity. (See Van Valin 1977, 1981). 
has not been described for any other language (See Everett 2011). With respect to morphosyntax, I have suggested that one of the fundamental principles in Kartiâna grammar, which has numerous effects on a variety of morphological and syntactic parameters, is the distinction between semantically intransitive and semantically transitive verbs. As noted in Everett (2006, 2010), verbs in the language are rigidly categorized into one of these two categories. Semantically intransitive verbs describe events in which only one participant is involved. Semantically transitive verbs describe events in which at least two participants are involved.

Like other languages such as Dyirbal and Latin (Dixon 1994), the language relies pervasively on a division between semantic intransitivity and transitivity. Crucially, though, this division is reified both morphologically and syntactically. Morphologically, semantically intransitive and transitive verbs are inflected differentially in declarative clauses, as we see in Table 1 . Verbs of the former type may be prefixed with an $i$ - affix, while verbs of the latter type may not. In fact, semantically transitive verbs may only be inflected with an $i$-prefix if they are embedded in negative or interrogative clauses (see discussion in Everett 2010).

\begin{tabular}{|l|l|l|l|}
\hline Intransitive Verb & Translation & Transitive Verb & Translation \\
\hline in i-taktaktana-t & 'I swam' & in naka-mi-t & 'I hit X \\
\hline in i-sombak & 'I looked around' & in naka-kip & 'I cut X' \\
\hline in i-hadna-t & 'I breathed' & in naka-i-t & 'I ate X' \\
\hline in i-sena-t & 'I crouched' & in naka-ma-t & 'I made X' \\
\hline in i-mbik & 'I sat' & in naka-mhip & 'I cooked X' \\
\hline in i-pikina-t & 'I ran' & in naka-hira-t & 'I smelled X' \\
\hline in i-tarika-t & 'I walked' & in naka-hit & 'I gave X' \\
\hline in i-tat & 'I went' & in naka-pit & 'I took X' \\
\hline in i-kisep & 'I jumped' & in naka-pidn & 'I kicked X' \\
\hline
\end{tabular}

Table 1: Examples of the semantic intransitivity/transitivity distinction in Karitiâna.

In addition to such morphological ramifications, this crucial semantic distinction surfaces syntactically. For instance, only semantically transitive verbs may be followed by a noun phrase that is not marked with an oblique marker, as we see in (1) and (2).
(1) ${ }^{*}$ in $i-m b i k$
bikipa
iN i-mbik bikipa-ti
1S INT-sit chair-OBL
'I sat in the chair.' 
(2) ${ }^{*}$ in naka-pidn bikipa-ti

in naka-pidn bikipa

'I kicked the chair.'

For a discussion of the other ways in which the distinction in question surfaces, see Everett (2010). As noted in that article and in Everett (2006), the theoretical framework of RRG readily accounts for such phenomena, since it places crucial emphasis on the part that macroroles play in structuring morphosyntax. From the perspective of RRG, all Karitiâna verbs are categorized as being semantically multivalent or semantically monovalent. In the case of verbs of the former type, their argument structure houses one, but no more than one, macrorole. In contrast, for verbs of the latter type, their argument structure hosts two or more macroroles. Put differently, such verbs require an 'actor' and an 'undergoer' (see e. g. Van Valin 2005).

The question addressed in the aforementioned pilot study was whether the deep division in Karitiâna between verbs requiring one macrorole and verbs requiring two macroroles impacts speakers' perceptions of nonlinguistic events. Put differently, the study explored whether Karitiâna speakers were more inclined to discriminate perceived events in accordance with semantic transitivity, when contrasted to speakers of a language like English, in which verbs are not rigidly categorized according to this parameter. In English, after all, verbs are generally fairly flexible and typically may occur in syntactically intransitive or transitive contexts. (In contrast, the transitivity distinction in Karitiâna is a rigid one, reflected in large measure syntactically as evident in (1) and (2) and in other features of the language not detailed here.) While the results of the study are not dispositive, they suggest that syntactically reified semantic phenomena may in fact impact nonlinguistic performance on relevant cognitive tasks.

Twenty-eight English speakers participated in the task. Fifteen Karitiâna speakers also participated. The latter were tested in the city of Porto Velho. The subjects were presented with a triad-based discrimination task, a type that has proven useful in other studies on relativistic effects (e. g. Lucy \& Gaskins 2001). The task consisted of fifteen separate stimuli triads, which were interspersed with distracter triads so as to prevent subjects from discerning the purpose of the study. Each triad was presented on the screen of a MacBook Pro. The triads consisted of three simultaneously presented abstract videos, two of which were presented 

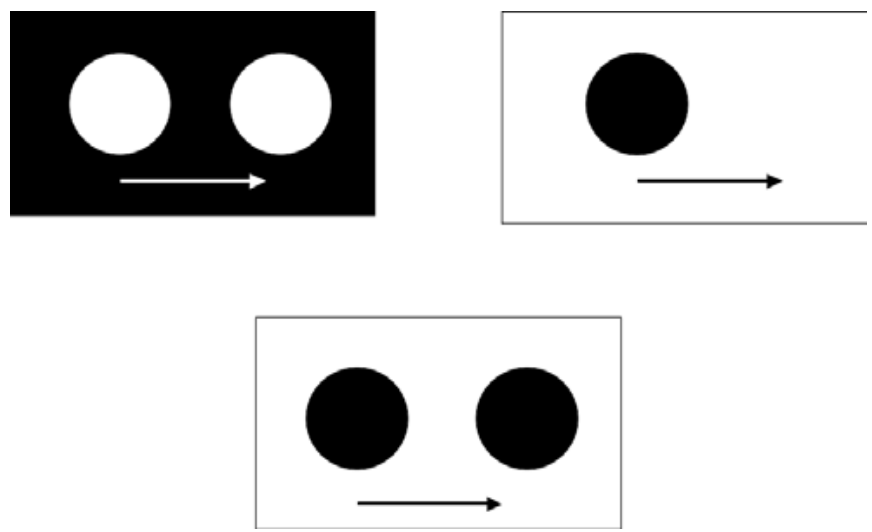

Figure 1: One of the fifteen triads employed in Everett (2014), in which discrimination could be based on a 'transitivity-oriented' choice or a color-oriented choice. Arrows represent direction of movement of a circle in the actual video.

on the top of the screen while a third was centered at the bottom of the screen, equidistant from the other two videos. Each video depicted the movement of abstract figures, inspired by the billiard-ball model of action framing, as utilized by Langacker (1987). One of the top videos consisted of the interaction/movement of two abstract figures (akin to abstract 'macroroles'), while the other top video depicted the movement of only one abstract figure (one 'macrorole'). The bottom video, referred to as the 'pivot', also depicted the interaction of two abstract figures. In this sense, it was visibly similar to the top video schematically depicting the interaction of two 'macroroles'. In every triad, however, the bottom event was also similar to the other top video according to another readily discernible factor. For example, in many cases the two videos depicted actions involving figures of the same color. As we see in Figure 1, for example, the pivot video and the topright video depict events involving black circles. In contrast, the pivot video and the top-left video both depict events involving two figures.

Subjects were asked to group two members of the triads, at the expense of another, by selecting the event at the top of the screen that they construed to be most similar to the bottom event. The heuristic conjecture at play was that Karitiâna speakers might be more likely to exhibit 'transitivity-oriented' discrimination, i. e. be more likely to group events based on the number of figures in the abstract videos, rather than according to some other factor such as the color of the figures. For instance, in the case of Figure 1, the relativistic account would 

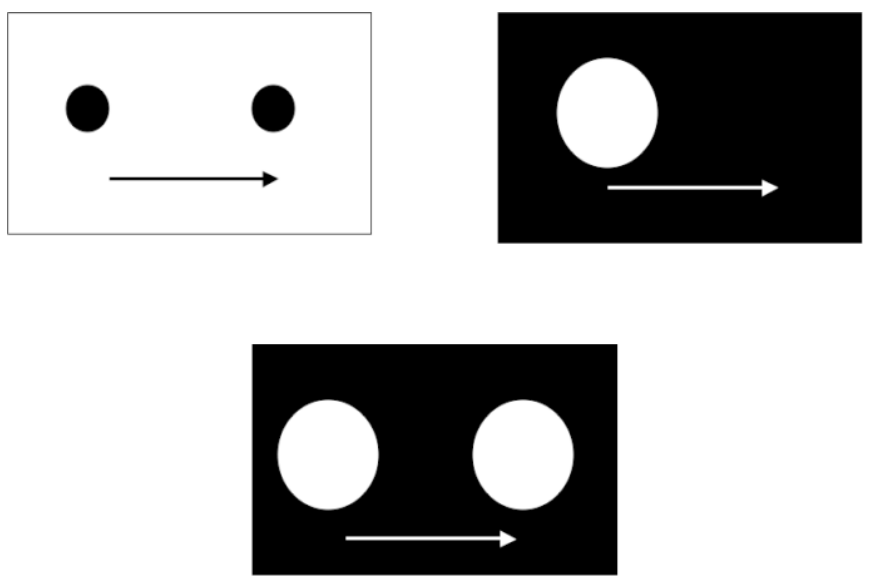

Figure 2: Another of the fifteen triads employed, in which discrimination could be based on a 'transitivity-oriented' choice or a size/color-oriented choice. Once again, arrows represent direction of movement of a circle in the actual video.

seem to predict that Karitiâna speakers would be more likely to group the bottom action with the top-left action, rather than the top-right one. The former discrimination strategy would rely on the number of participants in the perceived event, much as Karitiâna grammar relies so heavily on the distinction between one or more macroroles in verbal categorization. The latter discrimination would rely on similarity of color, a categorization strategy that has no analog in Karitiâna grammar. In the case of Figure 2, the relativistic account would once again predict that Karitianna speakers would more frequently group the bottom action with the top-left one (when compared with English speakers), since that grouping relies on 'transitivity orientation'. The alternate grouping in this case is favored by two categorization strategies: reliance on the identical color of the figures and reliance on the identical size of the figures. (It should be noted that the order of transitivity-based choices were counterbalanced across stimuli, so that some occurred in the top-left portion of the screen and an equal number occurred in the top-right portion of the screen.)

While we will not consider the results of the pilot study in great detail, they did generally support the relativistic hypothesis. Karitiâna speakers were significantly more likely than English speakers to utilize 'transitivity-orientation' in their action groupings. 
In the case of the English-speaking respondents, 107 out of 420 responses (28 participants $\mathrm{x} 15$ stimuli videos) were consistent with the transitivity-oriented discrimination pattern. In the case of the Karitiâna-speaking respondents, 103 out of 270 responses (18 participants x 15 stimuli videos) were consistent with the transitivity-oriented discrimination pattern. This difference was significant $(\mathrm{p}=0.0006$, re-

sponses a] to

the data as $\chi^{2}$ results ar€ the transitivit ina speakers c ers among eit

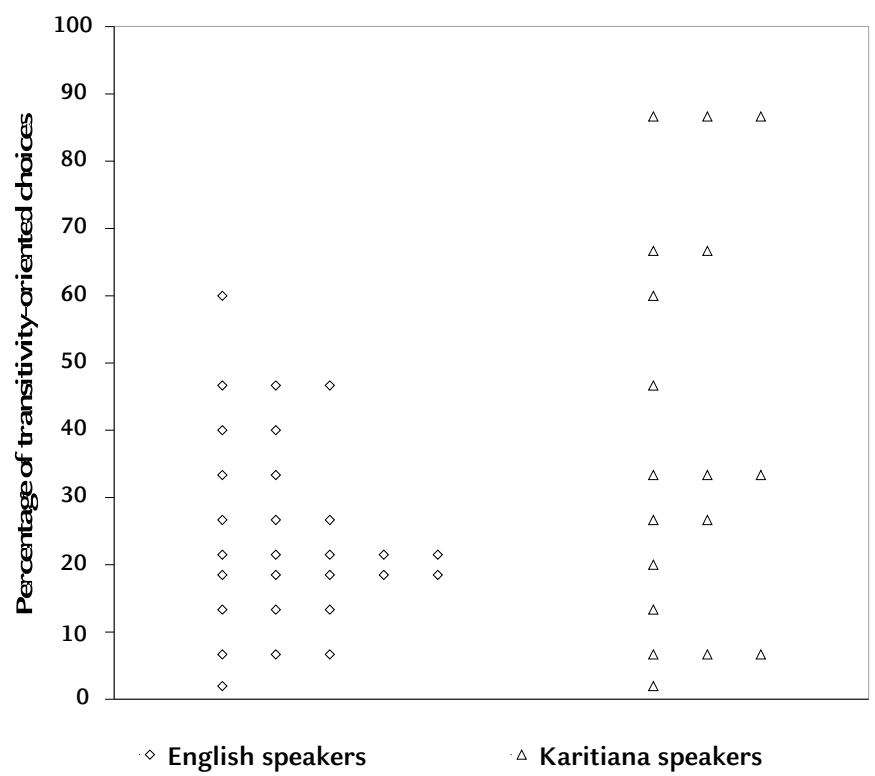

Figure 3: Plot of all individuals' response rates. Identical response rates within a group are staggered along the x-axis.

As we see in the figure, Karitiâna speakers' proclivity for transitivity-orientation in event discrimination varied significantly. In contrast, English speakers were more tightly clustered around the $20 \%$ range. As I discuss in Everett (2014), however, monolingual Karitiâna speakers were particularly likely to use transitivity- 
orientation as a basis for event discrimination, when contrasted to English speakers and more bilingual Karitiâna speakers. This finding lends greater support to the notion that the results are due to crosslinguistic variation rather than some other sort of cross-cultural variation.

In short, the findings in Everett (2014) suggest that a basic semantic division crucial to the grammar of the language, namely its reliance on a deep division between verbs with one macrorole or more than one macrorole in their logical structure, does appear to impact the performance of speakers of that language on nonlinguistic cognitive tasks. At the least, the results were consistent with such a claim. It is worth stressing that the deep semantic division in question is instantiated in numerous ways in the morphology and syntax of the language in question. Given that such a pervasive, syntactically reified grammatical distinction appears to impact nonlinguistic cognition (at least according to the results of the pilot study), it does not seem altogether unreasonable to believe that pervasive syntactic patterns could influence nonlinguistic thought. In the light of the study just discussed, not to mention the dozens of other recent studies on linguistic relativity, I believe that such an influence should at least be explored.

\section{The potential role of $\mathrm{RRG}$}

In Role and Reference Grammar, the syntactic representation of a clause and the semantic representation of that clause are directly mapped onto each other, and the mapping in question results from discourse-pragmatic factors, principally related to information structure. These discourse-pragmatic factors can of course vary from language to language, and this variance yields fundamental differences in the form of languages (see e. g. Van Valin 2005). The direct mapping between syntax and semantics characteristic of RRG makes it useful in the study of relativistic effects, since syntactic form is not presumed to be the result of abstract derivations that are inaccessible. As the reader is likely aware, many generatively influenced approaches to syntax treat it in a modular fashion, and syntax is often practically treated as being dissociated from real online performance and interactive discourse-pragmatic factors. This dissociation precludes the usage of such approaches in generating testable predictions regarding the putative influence of syntactic form on nonlinguistic thought. To reiterate, I am not claiming that the syntactic form of a given language does impact its speakers' nonlinguistic cogni- 
tion. I am simply suggesting that this unexplored possibility merits inquiry, and that RRG serves as a useful framework for such inquiry. This is so for two primary reasons. The first is that which I have already mentioned, namely that RRG actually allows for the direct mapping between a language's syntactic form and its speakers' conceptualizations of events, actors, and the like. The second reason is that RRG provides a toolkit of basic syntactic components that exist in the world's languages, but are deployed differentially by the grammars of different languages. These syntactic components include the NUCLEUS, the CORE, the PERIPHERY and other associated ones such as the precore slot and the PSA, or Privileged Syntactic Argument. I refer the reader to one of Van Valin's introductions to RRG for a description of these crucial components.

For our present purposes, I would like to evaluate the manner in which one of the crucial syntactic components of RRG, the PSA, might be used in the exploration of syntactic effects on thought. Much as RRG's emphasis on macroroles proved useful in the discussion of the event conceptualization study in the preceding section, its reliance on the notion of a PSA could prove useful in examining the effect of fundamental crosslinguistic disparities of syntax on speakers' conceptualizations of the roles of arguments within events.

RRG's precise formulation of the PSA is offered at various places in the literature (see e. g. Van Valin 2005), so I will not re-present a detailed account here. Bearing in mind the aforementioned point that there are two macroroles, actor and undergoer, I would like to focus on the following heuristic description of PSA's:

For a language like English... in an active voice clause with a transitive verb, the actor is the PSA, whereas for a language like Dyirbal, in an active voice clause with a transitive verb the undergoer is the PSA... These are the default choices; it is possible for an undergoer to serve as PSA in a passive construction in an accusative language like English or German, and it is likewise possible for an actor to serve as PSA in an antipassive construction in syntactically ergative languages like Dyirbal and Sama (Van Valin 2009: 17).

Note that these are the "default" choices for PSA's, and Van Valin notes in the same passage that some languages allow non-macroroles to serve as the PSA.

The nature of a language's PSA will of course have multifarious morphosyntactic effects on its grammatical relations. For instance, in those languages in which the PSA is typically the actor macrorole, we would expect there to be a variety of ways in which a nominative-accusative pattern should surface. With respect 
to syntax we would expect, for example, the actor argument of a transitive clause to function as the controller of a clause, governing coreferential deletion. Conversely, in those languages in which which the PSA is typically the undergoer, we would expect clear evidence of an absolutive-ergative alignment. We would expect, for instance, that the undergoer of a transitive clause would function as the controller of a clause, governing coreferential deletion.

English is of course a well-known case of a language in which the PSA is generally the actor of a transitive clause. As a result, the controller/pivot relationship indexes the actor, as in (3) and (4).

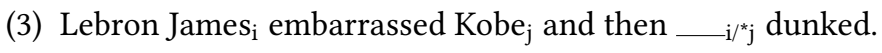

(4) Messi $i_{i}$ nutmegged Ronaldo $o_{j}$ and then _ ${ }_{i} /{ }^{*} j$ scored.

In contrast, in languages in which the PSA is typically the undergoer (which, admittedly, are much fewer in number), the controller/pivot relationship indexes that macrorole. If English were such a language, the deleted argument in (3) would refer to Kobe and the deleted argument in (4) would refer to Ronaldo. Dyirbal is an oft-cited case in which the controller-pivot relationship does in fact operate in this manner.

(5) \uma $_{j} \quad y a b u-\eta g u_{i} \quad$ bura- $n \_j^{\prime *}{ }_{i} \quad$ banaga- $n^{y} u$

father.ABSOLUTIVE mother-ERGATIVE see-NONFUTURE return-NONFUTURE

'Mother saw father and he returned.' (Farrell 2005: 51)

These sorts of examples are familiar to most linguists. Here is the crucial question in the context of the current discussion: Does the crosslinguistic syntactic variation described vis-à-vis PSA's and associated controller-pivot phenomena impact speakers' construal of entities in nonlinguistic contexts? Admittedly, many would be skeptical of such an influence and its existence likely strikes some as counterintuitive. Intuition can often mislead in such cases, however, and many of the relativistic effects described in my recent survey of research on this topic (Everett 2013a) are counter-intuitive to some but supported by robust empirical findings acquired through careful experimentation. (Here I am not referring to findings such as those from the pilot study described in the preceding section, but to better established findings associated with color perception, the construal of time, 
and numerical cognition, inter alia.) So we should consider how the matter could be approached empirically.

What sort of predictions might follow from the PSA-status discrepancy between languages like English and Dyirbal, assuming for the sake of argument that syntactic factors impact nonlinguistic construal? Given that the PSA governs coreference, we might expect that the referents represented by PSA's might have some sort of heightened topical salience in the minds of speakers. That is, since speakers are predisposed to recurrently refer to syntactically privileged arguments, the referents denoted by such arguments might be kept foregrounded by the speakers even in nonlinguistic contexts, since they are more likely than other referents to subsequently be indexed by clausal arguments. For instance, suppose a speaker of a language such as English witnesses the situation described by (4), though s/he does not utter anything in response to that perceived stimulus. We might expect that the referent construed as initiating the action (Messi), who would more than likely be encoded as the PSA should the clause in (4) be verbalized, might be more likely to be foregrounded in some manner. That is, given the likelihood that such a referent might come to have a central referential role in potential utterances, and given that such agentive referents have tended to have a central referential role in past utterances of the perceiver in question, the person witnessing the action may be predisposed (however slightly) to mentally track the player initiating the soccer maneuver in question.

Now suppose that a different person witnesses the same event, and that their native language is one like Dyirbal, in which the PSA is typically the undergoer of a transitive declarative clause. Even assuming that this person does not describe the event in question, we might expect the second referent in the perceived event (i. e. not the one initiating the action) to have relatively high salience for them, when contrasted to its salience for speakers of a language in which the PSA is typically the actor of a transitive declarative clause. After all, should such a witness choose to subsequently verbalize the event in question, s/he would likely need to refer multiple times to the person undergoing the soccer maneuver in question.

Note that this tentative hypothesis does not imply gross disparities in the way such actions are perceived by speakers of languages with such fundamentally disparate syntax. We might, for instance, expect the salience of agentive referents to be very high across all human observers in such nonlinguistic contexts. 
Nevertheless, the relative salience of agentive and patientive referents might vary somewhat across speakers of such languages. Recall that, for the pilot study described in section 2, both English and Karitiâna speakers tended to group events according to factors such as the color of objects in the events. So there were clear similarities between the populations' construal patterns. Nevertheless, the Karitiâna speakers evinced a greater tendency to utilize transitivity-oriented discrimination strategies.

How would we test the conjecture just offered? That is, how might we explore whether in fact speakers of languages with actor-based PSA's perceive stimuli in some differential manner, when contrasted with speakers of languages with undergoer-based PSA's? There are a number of factors that must be accounted for methodologically in such experimental work, not all of which I will address here (see Everett 2013a for a more detailed discussion of the methodological obstacles to relativistic research). Among other factors, we would need to ensure that the subjects participating in the experiment are native speakers of languages of the two basic syntactic types described above. For instance, we might contrast speakers of English and Dyirbal. Ideally, of course, we would conduct experiments among speakers of numerous languages that can be categorized into one of the two basic syntactic types mentioned. Utilizing speakers of many languages helps to reduce the influence of confounding cultural variables such as differences in literacy rates.

In order to uncover disparities in the nonlinguistic cognitive processes of two groups (or at least explore the possibility of such disparities), one needs to generate a series of experimental stimuli to be used in an entirely nonlinguistic task. Let me offer a sample stimulus that could potentially be used as a starting point for a pilot study examining the influence of PSA status on the nonlinguistic construal of perceived referents. In Figure 4 we see a basic static depiction of an event that could be presented via video on a computer screen, in a remote field setting or in a laboratory. The figure represents the movement of a large figure towards a smaller one. As the video progresses, the larger (more actor-like) figure alters the shape of the smaller one (more undergoer-like). The video might be described in English as follows: "The large dark circle squished the small gray one."

In one potential experiment, speakers of languages with different PSA types would be presented with the video stimulus depicted in Figure 4. The envisioned experiment would test the salience of the referents in the abstract video by forcing 


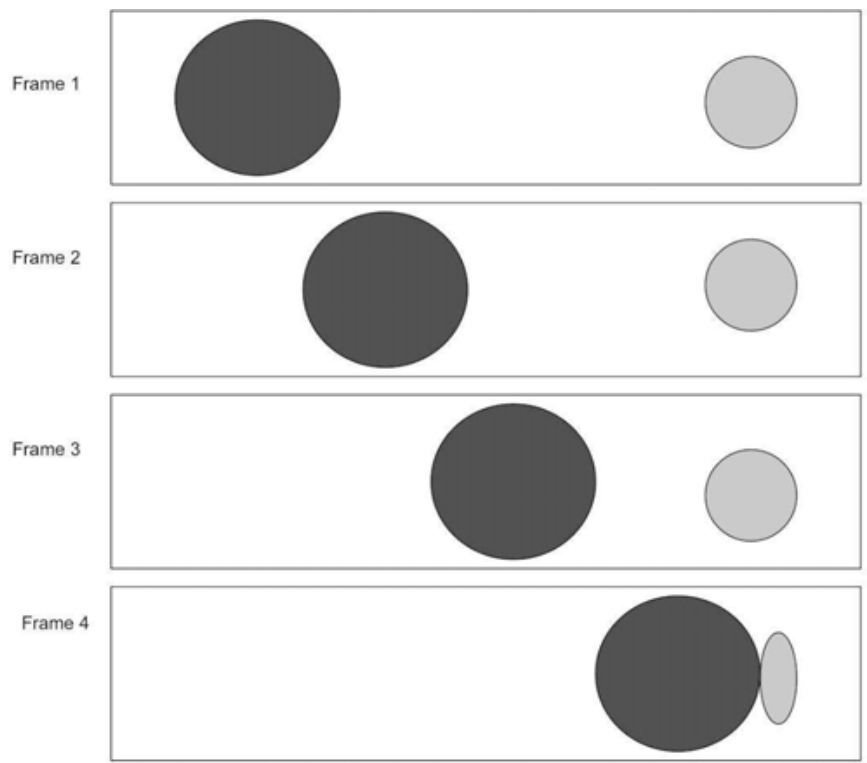

Figure 4: One potential stimulus for a task testing the salience of referents in a transitive event.

speakers to recall details of the referent initiating the action and the referent undergoing the action. For instance, in the task utilizing the stimulus depicted in Figure 4, participants might view the relevant video, unaware that they would subsequently be asked to recall details regarding the two referents in question. They might be presented with filler videos prior to or following (or both prior to and following) the stimulus video. Then, at some point they would be asked to recall the details of the event depicted in Figure 4. For instance, they might be asked to select the agentive referent (the large dark circle) from a number of depicted objects, all of which might be similar to the agentive referent but only one of which would be identical. Similarly, they might be asked to select the patientive referent from a number of depicted objects, all of which would be similar to the patientive referent but only one of which would be exactly the same. In this manner, the relative topical salience of the two kinds of referents might be tested across the two linguistic populations. Crucially, the entire task would be nonlinguistic.

Obviously, numerous stimuli of the sort depicted in Figure 4 would have to be generated, and numerous participants would be required for each language 
group represented in the experiment. Ideally, a third group of participants might be recruited. This group would be bilingual, speaking both a language with an actor-oriented PSA and an undergoer-oriented PSA. Via this sort of systematic exploration of this topic, we might uncover cross-population disparities that are consistent with a relativistic interpretation. For example, suppose that speakers of a language like Dyirbal were relatively adept at recalling details regarding the undergoer-type referents, while speakers of a language like English were relatively adept at recalling the features of actor-type ones. Furthermore, suppose that participants that spoke both kinds of languages exhibited a sort of mixed performance, vis-à-vis referent recall. A distribution of recall strategies of this sort would hint at syntactic effects on nonlinguistic cognition. Such results would not necessarily be conclusive, and a number of external variables would need to be ruled out. Nevertheless, we can get a sense of how such an experiment might be carried out in order to test the role of PSA status in nonlinguistic thought. (Interestingly, similar methods have been sucessfully employed, with videos of real [non-abstract] events, in a recent related study (Fausey \& Boroditsky 2011).)

\section{Discussion and conclusion}

In the last several decades there has been an explosion of research on linguistic relativity. Much of this work has suggested fairly conclusively that linguistic disparities help generate nonlinguistic differences in cognitive processes across human populations. The work in question is generally based on morphological and lexical differences between languages (see Everett 2013a), and no studies have exclusively explored the potential effects of syntactic disparities on nonlinguistic thought. In this chapter I have summarized evidence from a recent pilot study suggesting that morphosyntactic differences between Karitiâna and English speakers appear to impact their nonlinguistic construal of events. Relying on RRG, I demonstrated how the morphosynctactic differences in question are the result of the centrality, in Karitiâna grammar, of the number of macroroles housed by each verb. In other words, I suggested that RRG serves as a useful framework for describing the crosslinguistic disparities that appear to yield nonlinguistic disparities in event construal.

In a similar vein, I suggested that RRG's straightforward approach to syntax, according to which syntax is mapped directly on semantic form and not mediated 


\section{References}

by some modular algorithm, offers a useful framework for future investigations of the role of syntax on nonlinguistic cognition. In particular, I have suggested that the basic distinctions between PSA types presented in RRG allow for the straightforward generation of testable hypotheses on the influences of syntax on nonlinguistic thought. This does not imply, of course, that such influences will in fact surface in future experimental work of the sort hinted at above. I am simply suggesting that the typologically well-informed approach of RRG offers a useful point of departure for future explorations of the type described here.

\section{References}

Dixon, R. 1994. Ergativity. Cambridge: Cambridge University Press.

Evans, N. \& S. Levinson. 2009. The myth of language universals. Language diversity and its importance for cognitive science. Behavioral and Brain Sciences 32: 429-492.

Everett, C. 2014. Evidence for relativistic effects in the construal of transitive events. Selected papers from UK-CLA Meetings, Vol II: 84-101.

Everett, C. 2013a. Linguistic relativity: Evidence across languages and cognitive domains. Berlin: De Gruyter Mouton.

Everett, C. 2013b. Independent cross-cultural data reveal linguistic effects on basic numerical cognition. Language and Cognition 5: 99-104.

Everett, C. 2011. Variable velic movement in Karitiâna. International fournal of American Linguistics 77: 33-58.

Everett, C. 2010. Negation and the untransitive category in Karitiâna. Proceedings of the Berkeley Linguistics Society 35: 379-390.

Everett, C. 2006. Patterns in Karitiâna: Articulation, perception, and grammar. Rice University dissertation.

Farrell, P. 2005. Grammatical relations. Oxford: Oxford University Press.

Fausey, C., \& L. Boroditsky. 2011. Who dunnit? Cross-linguistic differences in eye-witness memory. Psychonomic Bulletin \& Review 13: 275-280.

Landin. D. 1984. An outline of the syntactic structure of Karitiana sentence. In B. Dooley (ed.), Estudos Sobre Línguas Tupí do Brasil, 219-254. Brasilia: SIL.

Langacker, R. 1987. Foundations of cognitive grammar. Palo Alto: Stanford University Press. 
Lucy, J. 1992. Language diversity and thought. Cambridge: Cambridge University Press

Lucy, J. \& S. Gaskins. 2001. Grammatical categories and the development of classification preferences: A comparative approach. In M. Bowerman \& S. Levinson (eds.), Language acquisition and conceptual development, 257-283. Cambridge: CUP.

McGregor, W. 2009. Typology of ergativity. Language and Linguistics Compass 3: 480-508.

Van Valin, R. D., Jr. 2009. An overview of Role and Reference Grammar.

Available online: http://linguistics.buffalo.edu/people/faculty/vanvalin/rrg/ RRG_overview.pdf.

Van Valin, R. D., Jr. 2005. Exploring the syntax-semantics interface. Cambridge: Cambridge University Press.

Van Valin, R. D., Jr. 1981. Grammatical relations in ergative languages. Studies in Language 5: 361-394.

Van Valin, R. D., Jr. 1977. Ergativity and the universality of subjects. Proceedings of the Chicago Linguistic Society 13: 689-706.

\section{Author}

Caleb Everett

Department of Anthropology

University of Miami

caleb@miami.edu 